\title{
CÁRCEL PARA LA CIUDAD \\ Estudio sobre los equipamientos carcelarios en Colombia
}

\author{
Daniel Eduardo Forero Martin \\ Universidad Nacional de Colombia, Sede Bogotá \\ Director: Sergio Moreno Ballesteros \\ Email: dforero741@gmail.com
}

\section{RESUMEN}

La cárcel es un equipamiento que influye en la sociedad. Clasificar los centros penitenciarios, definir su población, crear dinámicas de interacción y mantener el contacto con el resto de la sociedad con un enfoque hacia la resocialización podría descongestionar los centros carcelarios.

Este estudio explora los impactos físicos de una problemática carcelaria, sin tener en cuenta la arquitectura de las cárceles; analizándo su relación con el contexto. Se plantearán principios de aprovechamiento de infraestructura que beneficiaría a la población privada de la libertad y garantizaría el derecho a la ciudad para todos los ciudadanos. Investigación generada para posterior prueba y evaluación en proyectos futuros.

Palabras clave: Cárcel, ciudad, diseño urbano, resocialización.

\section{ABSTRACT}

Prisons are equipments that influence and have an impact on society. Classifying penitentiaries, defining its population, and setting dynamics of interaction between prisons and society through approach towards resocialization could relieve and reduce prison overcrowding.

This study explores how to tackle the structural, physical and perceivable affairs in the context of prisons, without taking into account its architecture. To do so, it explores the current interventions performed in different prisons and their impact. Furthermore, it aims to provide principles and procedures to make the most of penitentiaries' infrastructure, which could benefit inmates and also guarantee the city inhabitants a "right to the city".

This research has the aim of being applied and evaluated from the proposed approaches and models of long term intervention.

Key words: Jail, city, urban design, resocialization. 


\section{ALGUNOS ANTECEDENTES}

La cárcel existe en todas las sociedades, sin importar su modelo político y económico adoptado, este equipamiento de justicia cumple la función de privar de la libertad y tratar a las personas que infringen la ley establecida; históricamente la prisión surge a partir de la necesidad de castigar y ejercer control sobre los individuos. Existe una relación entre edificios de cárceles, manicomios, hospitales y la ciudad, con el tiempo se representaron en edificios de calabozos, claustros, panóptico, complejos carcelarios entre otros. En Colombia la cárcel genera el poder de privar la libertad a los individuos, lo cual permite llevar un control social parcial. La acumulación de población por falta de definición judicial, la reinserción en el delito y el alto hacinamiento en las cárceles genera que no se dispongan de los espacios necesarios para una resocialización y no se logre una adecuada clasificación de los internos generando problemas de convivencia en el interior como en el exterior de los establecimientos.

La situación latinoamericana pasa por un alto nivel de hacinamiento, los presos sin sentencia llenan cada vez más las prisiones, tal vez por la reincidencia en el crimen o por el desinterés ante estos establecimientos los cuales solo son vistos como herramienta de castigo sin explorar temas como reeducación, readaptación social, rehabilitación o la reincorporación social; entre las investigaciones que se han preocupado por abordar esta problemática en la investigación titulada "La necesidad de creación de una cárcel sustentable para la verdadera reinserción (Oscar Francisco Plaza Delgado, 2012). Aborda desde el componente jurídico el desarrollo de los sistemas socio ecológico para lograr una nueva configuración en las tres dimensiones centrales del desarrollo sustentable para una cárcel sustentable: la económica, la social y la ambiental. Recopilando las consideraciones de usar paneles solares, limpieza de agua reciclada, aprovechamiento de la luz natural para explotar la agricultura como fuente de trabajo, todo ello para concientizar la posibilidad de aprovechar el tiempo de los internos que deseen redimir pena a cambio de una remuneración. Significa esto que Mediante la solución física y la debida relación del equipamiento con el contexto, se podría afrontar única y exclusivamente el tratamiento y la resocialización de los internos.

En el estudio respecto a la ubicación de los nuevos centros penitenciarios, la investigación "La cárcel. Un nuovo carcere per Bogotá" (Andrea Baldacci, 2014). plantea una nueva cárcel en Bogotá en el barrio Liston argumentando que la proximidad de la cárcel al centro de la ciudad beneficia la complementación de servicios con otras cárceles relativamente cercanas como la cárcel Modelo y el Buen Pastor acortando los tiempos de desplazamientos dentro de la ciudad de Bogotá entre establecimientos carcelarios y jurídicos, el proyecto consta de un espacio libre en primera planta dejando la máxima permeabilidad para suplir las necesidades complementarias de la demanda educativa como parques y áreas de talleres. Todo esto dispuesto para reeducar y rehabilitar tanto la población privada de la libertad como la comunidad, solucionando los conflictos de carencia de infraestructura pública en el sector con el fin de añadir una red de proyectos que sean complementarios entre ellos mismos.

Por otra parte el tema de tratamiento también es abordado en la investigación" la arquitectura como recurso para la resocialización en las cárceles colombianas". (Jaime Alberto López Mejía, 2013) sin entrar en detalle al producto arquitectónico, el autor empieza con un programa general de áreas hacia el exterior del complejo, con los siguientes espacios: carretera de acceso, parada de transporte público y privado, estacionamientos, helipuerto y plaza principal. Esto significa que aunque básicos los espacios, son pocos en relación a la necesidad de todos los componentes de la cárcel, evidenciando la necesidad de empezar a diseñar las cárceles hacia afuera con la debida planeación y relación urbana para que se justifique su inversión a largo plazo; este conflicto de la relación entre cerramiento agresivo y ciudad se podría relacionar con los conceptos de Jane Jacobs y el trabajo con bordes de los parques, en el cual sentencia que ambos espacios pueden ser populares o impopulares, todo depende del ofrecimiento a la sociedad, la variedad de usuarios en distintos horarios pueden representar un bien económico para la ciudad, mientras que la disposición de elementos va ligado con la calidad del paisaje en la cual entre menos monótono mucho mejor para generar recorridos interesantes, el problema es que cuando existe inactividad se crea una barrera virtual que advierte a los transeúntes a alejarse de estos espacios focos de inseguridad generada por la falta de diversidad funcional.

\section{PROBLEMÁTICA}

En Colombia las cárceles son consideradas equipamientos que afectan el contexto urbano de forma negativa, la demanda de infraestructura urbana ligado a la falta de planeación generan conflictos de funcionamiento dentro de la trama urbana, la improvisación y la falta de apropiación de estos equipamientos en un país en el cual los lazos familiares son muy importantes y generan gran demanda, son los factores que evidencian un problemática carcelaria dentro y fuera de los establecimientos. 


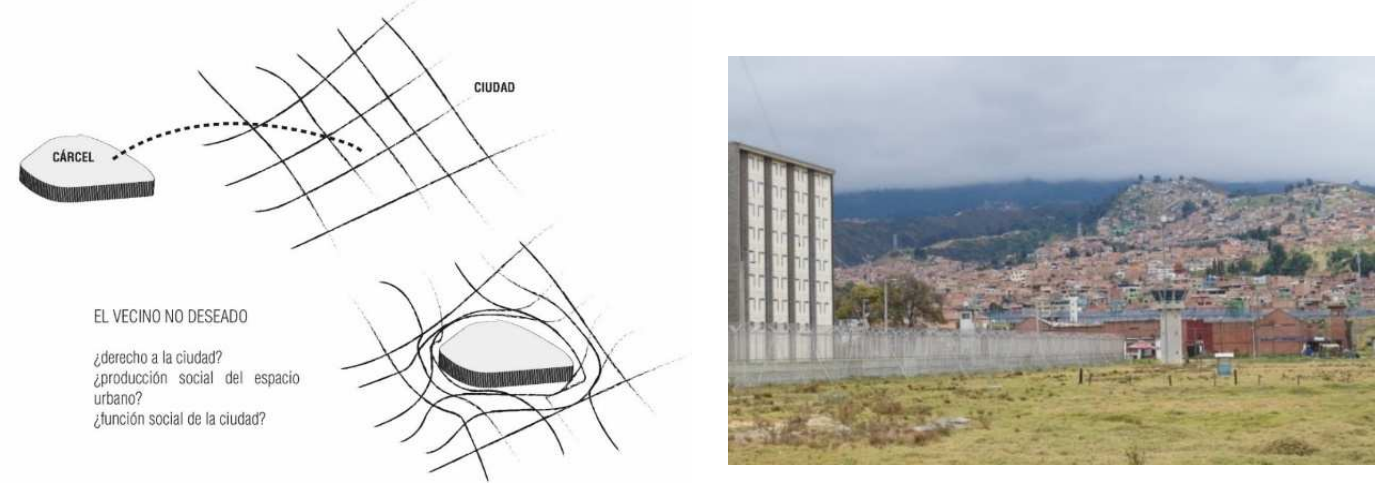

Figura 2.1: la cárcel el vecino no deseado esquema elaborado por el autor. (Izquierda)

Figura 2.2: fotografía cárcel la picota Bogotá; captada el autor. (Derecha)

La falta de equipamientos carcelarios genera hacinamiento, esta situación conlleva a que se mezcle toda la población recluida, al no tener una debida clasificación se presta para reincidencia del individuo en el delito generando un mayor hacinamiento, esta condición es casi un ciclo repetitivo. Por esto se plantea la siguiente duda ¿Es posible diseñar un equipamiento carcelario que sea un espacio de integración urbana, el cual tenga multifuncionalidad para suplir la carencia de infraestructura en las ciudades?

Para abordar este tema inicialmente se toma como referente teórico a Foucault, quien ve la prisión como un sistema de represión, el cual buscaba reeducar los individuos pero con el tiempo se presentaba la contra productividad de generar más delincuentes; el autor indaga sobre el por qué las prisiones siguieron existiendo a pesar de todo. Aborda temas como la necesidad del poder y el aprovechamiento de los criminales para utilidad, planteando postulaciones como; "cuando más delincuentes existan, más crímenes existirán, cuanto más crímenes hayan, más miedo tendrá la población y cuanto más miedo tenga la población, más aceptable y deseable se vuelve el sistema de control policial. La existencia de ese peligro interno es una de las condiciones de aceptabilidad de ese sistema de control, lo que explica por qué en los periódicos, la radio y la televisión en todos los países del mundo sin excepción se le concede tanto espacio

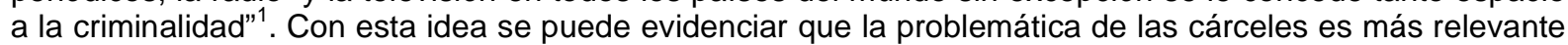
de lo que parece pues no solo afecta a los reclusos sino a la ciudadanía en general.

La sociedad genera mecanismos para castigar mas no para re-educar mediante elementos para dominar con el poder, actualmente la responsabilidad de vigilar es de parte del estado, dejando a la sociedad fuera del proceso de reivindicación del individuo privado de la libertad, por esta razón el sistema pierde su meta y las cárceles se vuelven "universidades del crimen", la reincidencia de delincuentes continuarían en un ciclo sin fin. "Es posible un tratamiento humano en la implementación del dominio y poder mediante alternativas sociales, las cuales se podrían aprovechar para la re-educación de los condenados con el objetivo de redención de penas mediante trabajo paso a paso el cual logre preparar gente dispuesta a adaptarse con derechos y deberes bajo un contrato social” ${ }^{3}$

Lo anterior se evidencia con datos oficiales de la entidad administradora de las cárceles en Colombia el Instituto Nacional Penitenciario y Carcelario INPEC respecto al hacinamiento nacional "a 31 de abril de 2015 en Colombia se registraban 167.133 personas privadas de libertad. La población carcelaria y penitenciaria a cargo del INPEC, supera la capacidad debido al constante crecimiento en el número de reclusos y reclusas, el instituto presento una sobre población de 41.504 personas, lo que significa un índice de hacinamiento de $53.3 \%$ puntos porcentuales por encima del mes anterior"4, La demanda inminente carcelaria en Colombia ha generado que la resocialización de la población reclusa se vea inconclusa debido a que los espacios destinados para este fin no pueden ser utilizados por el alto nivel de hacinamiento.

\footnotetext{
${ }^{1}$ Michel Foucault (conferencia pronunciada en 1976 en Brasil. Publicada en la revista Barbarie, N- ${ }^{\circ} 4$ y 5, 1981-2, San Salvador de Bahía, Brasil.)

${ }^{2}$ Término popular en el cual cuando en la cárcel existe alta reinserción se adopta como si la persona privada de la libertad utilizara el establecimiento para hacer carrera en el crimen.

${ }^{3}$ El contrato social: o los principios del derecho político, más conocido como El contrato social, es un libro escrito por Jean- Jacques Rousseau y publicado en 1762.

${ }^{4}$ INPEC informe estadístico abril 2015
} 
La reinserción social se debería dar a través de la configuración propia de un Estado con capacidad de desactivar la guerra, Dada la magnitud de los impactos psicosociales en la población colombiana causada por el conflicto armado. Los requerimientos básicos para dar abordar una resocialización son los siguientes:

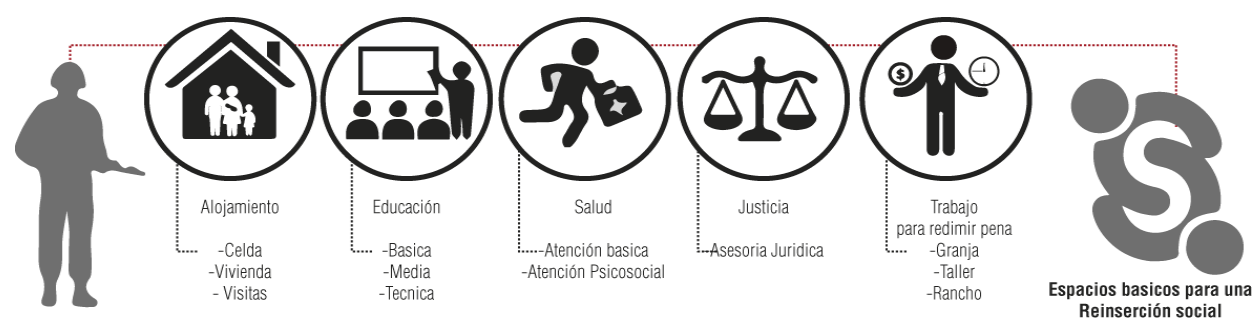

Figura 2.3: Requerimientos para la reinserción social, esquema elaboración propia.

Generando nuevos equipamientos enfocados en la resocialización del gran número de actores del conflicto colombiano, los cuales deberían ser dotados de los recursos técnicos y financieros para garantizar la atención psicológica, psicosocial y la rehabilitación de las poblaciones afectadas por el conflicto, con enfoque diferencial. Lamentablemente todo esto no se da debido a que actualmente no es una prioridad de política pública.

\section{METODOLOGÍA}

Se divide en tres pasos, el primero paso es realizar un inventario sobre las clasificaciones de los tipos de cárceles existentes en Colombia junto con sus problemas urbanos, en el segundo paso se analiza una matriz de impacto urbano de alguno centros carcelarios seleccionados, en el último paso recopilando la información conseguida se presentan principios y consejos de intervención para generar alternativas al planteamiento de los nuevos establecimientos carcelarios.

\section{CLASIFICACION DE LAS CARCELES}

La situación general de las cárceles en Colombia es crítica, debido a que la mayoría de establecimientos tienen más de 30 años, casi sin intervención de mantenimiento básico; actualmente se están desarrollando nuevos proyectos para atender el déficit de establecimientos penitenciarios lo cual refresca el panorama pero es importante empezar a generar nuevas alternativas y dinámicas de establecimientos de reclusión. A continuación se hace una clasificación de las cárceles en Colombia:

\subsection{Clasificación por Forma y tipología}

La clasificación en el componente de forma y tipología, aborda las tipologías de cárceles y proyecta que las cárceles de tipo agrícola y los complejos penitenciarios de gran tamaño solo se pueden desarrollar en suelos rurales debido a que requieren de un área extensa. 


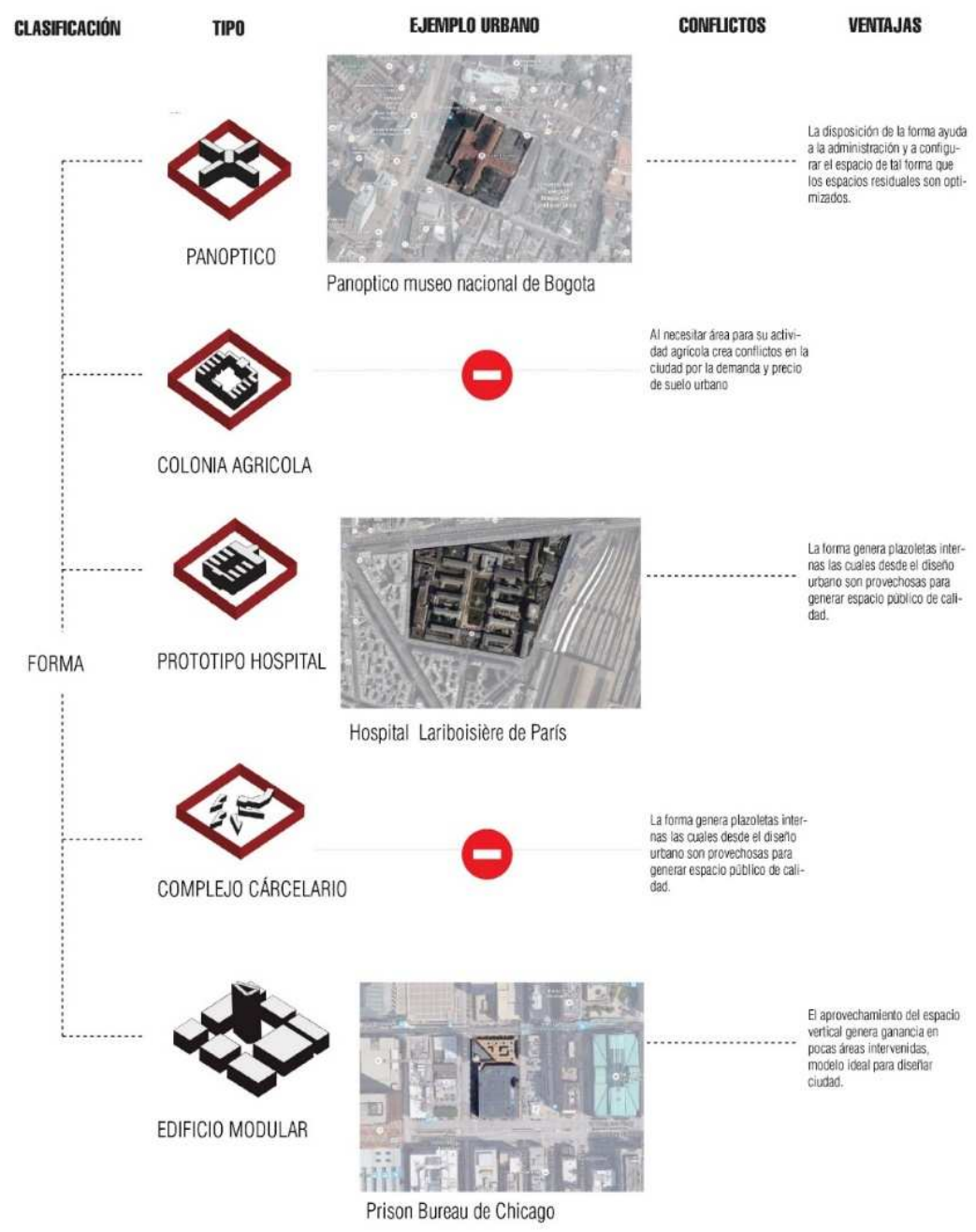

Figura 4.1: Pertinencia de las cárceles según su forma en contextos urbanos, elaboración propia.

\subsubsection{Cárcel horizontal}

La principal función de una cárcel es contener la población requerida por la justica, existen dos modelos de disposición de elementos dentro de la cárcel los cuales son: forma horizontal y vertical; estos modelos son utilizados dependiendo la ubicación, para el sector rural la solución horizontal es la más usada debido a que no los limita el espacio, mientras que en las ciudades se usa el modelo vertical debido a que aprovecha el área en altura. A continuación se presenta los modelos.

El principal problema de este modelo es la agresividad de su cerramiento que genera servidumbre y la extensa área de aislamiento podría ser aprovechada económicamente o funcionalmente para que no se generen los focos de contaminación que actualmente se evidencian en cárceles de este tipo. 

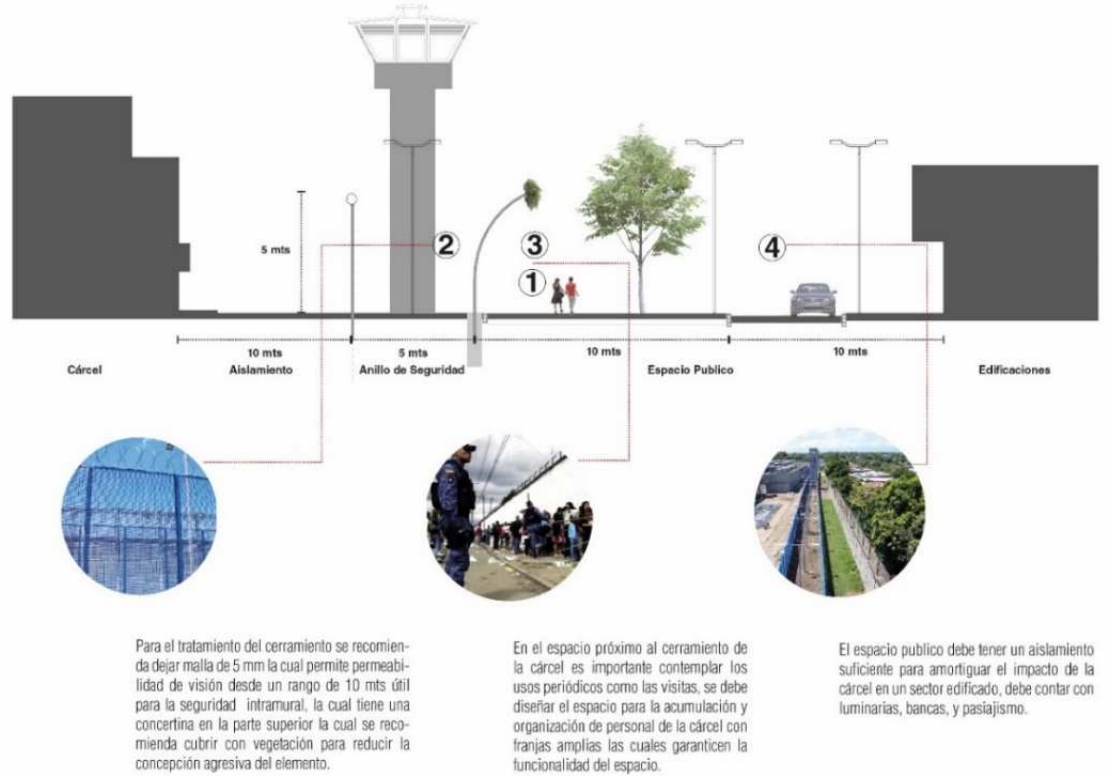

Figura 4.1.1: Consideraciones para el manejo del perímetro del modelo de cárcel horizontal, elaboración propia.

\subsubsection{Cárcel en altura}

El modelo en altura tiene como caracteristica que la edificio logra adaptarse a una trama consolidad generando gran cantidad de espacio publico en primer piso y permite la permeabilidad de circulaciones para los usuarios.

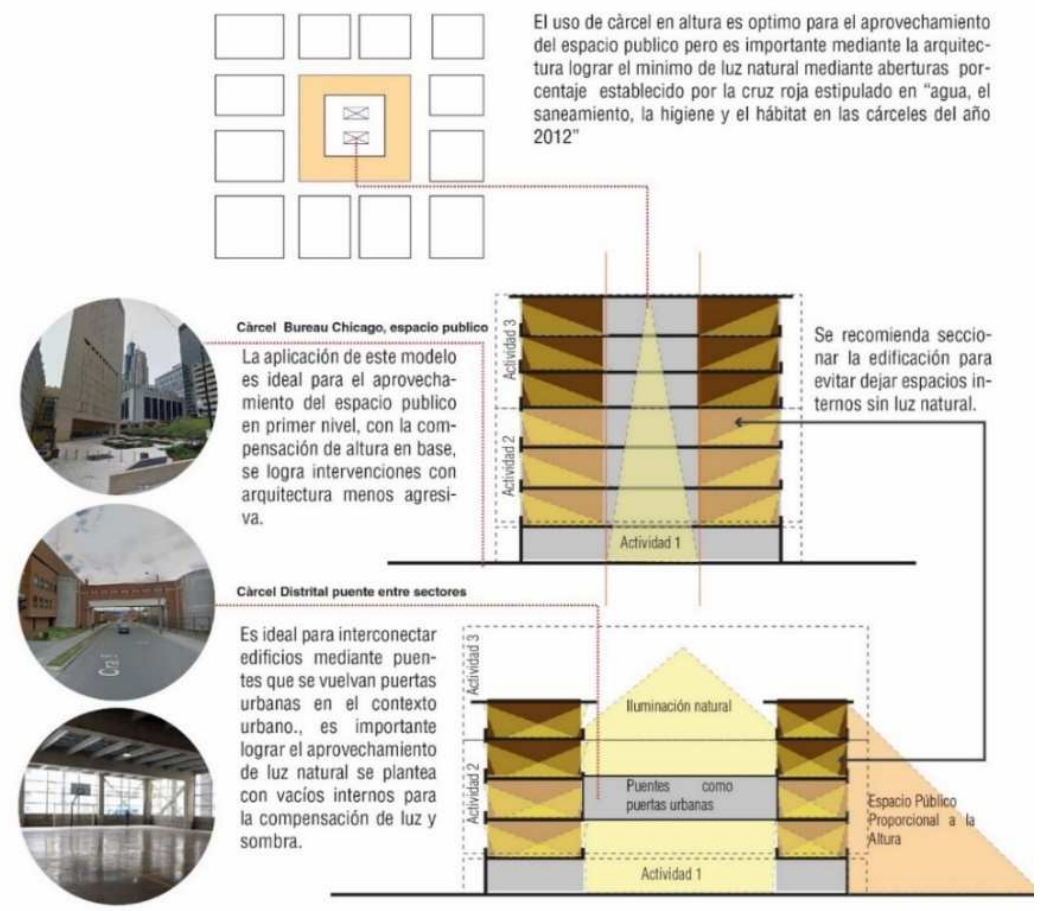

Figura 4.1.2: Consideraciones para el modelo en altura, elaboración propia.

Este modelo tiene ventajas significativas para la aplicación en centros urbanizados, debido a que ocupa poco espacio y se puede relacionar su infraestructura por modelos verticales de servicios, las problemáticas que genera son contaminación auditiva y conflictos de circulación en la primera planta, pero es totalmente tratable desde la arquitectura contemplando la gran demanda de usuarios para que tenga un óptimo funcionamiento. 


\subsection{Clasificación por capacidad}

En Colombia el INPEC ${ }^{5}$ es el organismo administrativo de los establecimientos penitenciarios a nivel nacional, y estos complejos realizan la función de privación de libertad intramural y estas se diseñan teniendo en cuenta el número de internos que puede soportar su capacidad inicial ${ }^{6}$, a continuación se comparan la clasificación por capacidad evidenciando que las cárceles para más de 1500 internos se recomienda dejar fuera de las ciudades debido a que el impacto y el gran espacio necesario para su funcionamiento no se puede dar fácilmente dentro de las tramas urbanas.

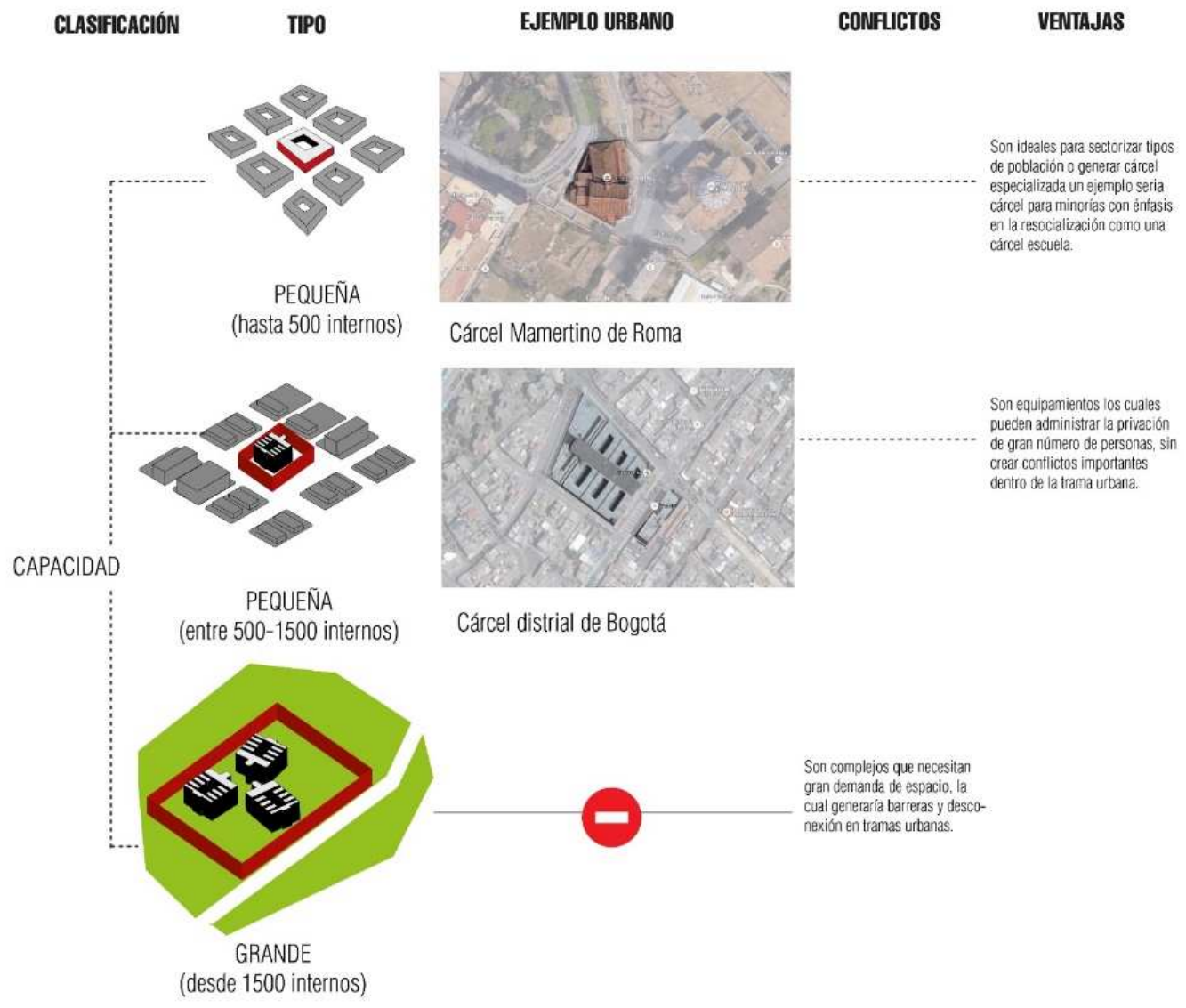

Figura 4.2: Pertinencia de las cárceles según su capacidad en contextos urbanos, elaboración propia.

\subsection{Clasificación por niveles de seguridad según el INPEC ${ }^{7}$}

El modelo progresivo de tratamiento busca la integración social del recluso teniendo en cuenta el cumplimiento de la pena, la naturaleza del delito y la conducta asumida por el interno para enmendar su error. Este sistema comprende la implementación de unas fases que van graduando los niveles de seguridad del condenado:

\footnotetext{
${ }^{5}$ Instituto Nacional Penitenciario y Carcelario de Colombia - INPEC

${ }^{6}$ Clasificación asignada según el documento INPEC - pautas carcelarias 2012

${ }^{7}$ Instituto Nacional Penitenciario y Carcelario de Colombia - INPEC
} 
NIVELES DE SEGURIDAD

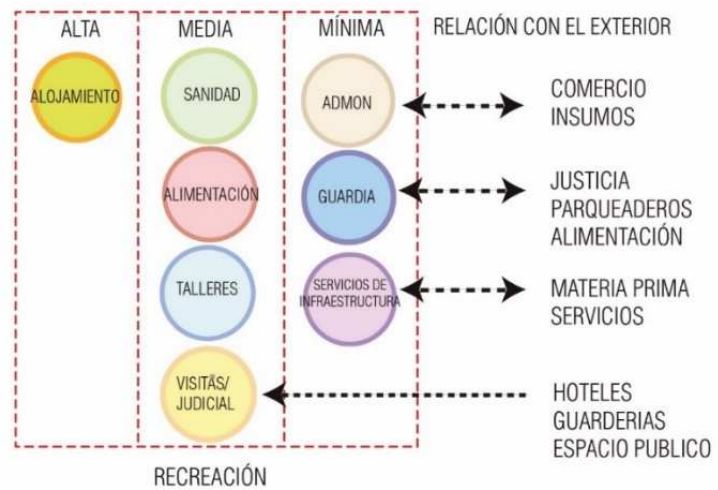

Figura 4.3: Relación con el exterior según nivel de seguridad, elaboración propia.

A continuación se compara la clasificación por nivel de seguridad en la cual la población de mínima seguridad cuenta con beneficios los cuales pueden ser útiles para la sociedad por esta razón para una cárcel urbana se recomienda aprovechar todas las dinámicas que genera hacia el interior de la cárcel como beneficio bilateral, mediante funciones y servicios sociales como ejes conectores de la relación entre comunidad y establecimiento.

CLASIFICACIÓN

TIPO

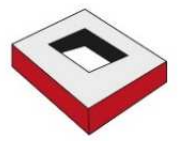

MìNIMA
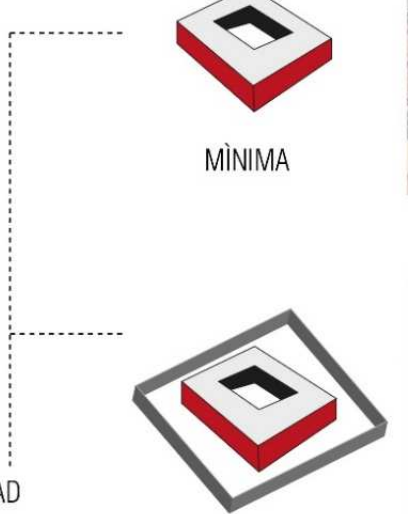

MEDIA

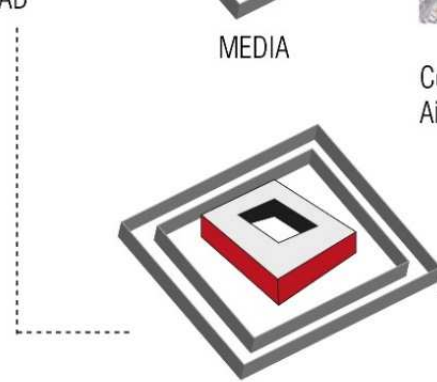

ALTA
EJEMPLO

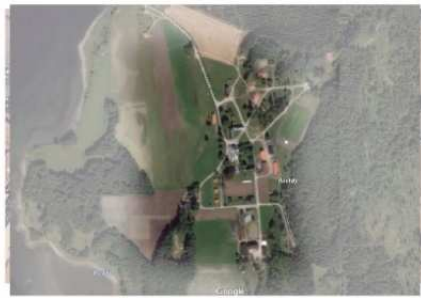

Bastoy Noruega

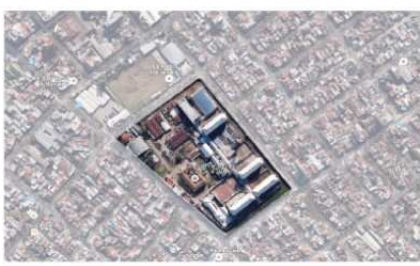

Complejo penitenciario Caba de Buenos Aires
CONFLCTOS

\section{VENTAJAS}

Al ser cárceles que disponen todo para el tratamiento de los internos es ideal disponerlos en zonas habitadas para que se adapten a la sociedad

Figura 4.3.1: Pertinencia de las cárceles según nivel de seguridad en contextos urbanos, elaboración propia. 


\subsection{Clasificación por condición jurídica y tipo de población}

La privación de la libertad se divide en dos condiciones jurídicas (sindicado y condenado) y socialmente subdivide la sociedad en grupo sociales con características propias en la cual cada población requiere espacios y funciones específicas por esta razón es importante generar una clasificación prioritaria al utilizar los centros carcelarios debido al conflicto de intereses poblacionales. A continuación se presentan las diferencias de la población sindicada y condenada en cuanto a tiempos de estancia, actividad principal y requerimientos básicos de espacios.
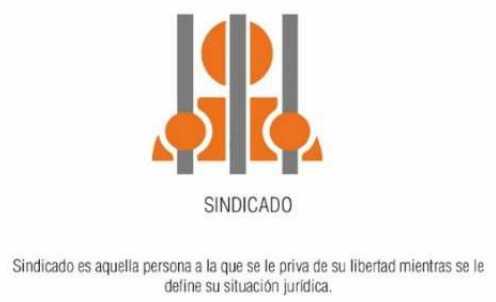

tiempo de estancia:

actividad principal:

requerimientos espaciales:

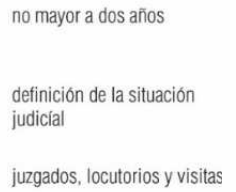

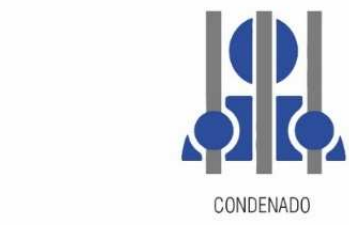

Condenado es aquella persona a la cual el sistema judicial le ha imputado una condena de privación de libertad dependiendo la pena

actividad principal:

requerimientos espaciales redención de pena mediante trabajo, educaciòn y enseñansa

aulas, talleres y visitas

Figura 4.4: definición persona sindicada y condenada, elaboración propia.

Para el INPEC ${ }^{8}$ es un problema que los sindicados se encuentren en centros localizados fuera de los centros urbanos, debido a que el desplazamiento permanente de cada interno a los juzgados genera un desgaste de infraestructura vehicular y utilización de personal no disponible, debido a que cada interno tiene cita única para sus trámites jurídicos, Cuando la población es condenada es importante empezar a clasificar internos por tiempo y nivel de peligrosidad debido a que no se podría dar tratamiento de resocialización si no se cumple con la debida disposición de los internos, por esta razón se recomienda las personas de mayor grado de peligrosidad sean trasladados a centros alejados de los cascos urbanos, para que se dediquen a la redención de pena y los internos debidamente clasificados en mínima seguridad y con poco tiempo para cumplir su pena se les puede generar alternativas de resocialización mediante sus experiencias vividas como generar relaciones entre escuela cárcel para aprovechamiento mutuo.

\subsection{Grupos sociales}

La reforma al Código Penitenciario y Carcelario de Colombia ${ }^{9}$ en materia de Derechos Humanos estableció el enfoque diferencial en materia de género, edad, grupo étnico, entre otros clasifica a las personas en grupos sociales para evitar conflicto en la convivencia, cada una de estas poblaciones cuenta con características específicas y disposición de servicios diferentes mediante su condición entre los cuales están mujeres, niños, tercera edad, LGTB, minorías, servidores públicos, indígenas, inimputados psiquiátricos. La clasificación diferencia el grupo de población debido a que algunos cuentan con espacios específicos a tener en cuenta como lo es el caso de los campesinos e indígenas privados de la libertad los cuales deberían tener mucha más área productiva para para poder realizar sus actividades agrícolas, como se ve en el caso del establecimiento colonia agrícola Acacias la cual está focalizada en ser una cárcel productiva atravesó de la crianza de ganado y actividades agrícolas.

A continuación se presenta un ejemplo de tres variables de clasificación unidas, en la cual el tipo de población, la condición jurídica:

\footnotetext{
${ }^{8}$ Instituto Nacional Penitenciario y Carcelario de Colombia - INPEC

${ }^{9}$ Ley 1709 de 2014 por medio de la cual se reforman algunos artículos de la ley 65 de 1993, de la ley 599 de 2000 , de la ley 55 de 1985 y se dictan otras disposiciones.
} 


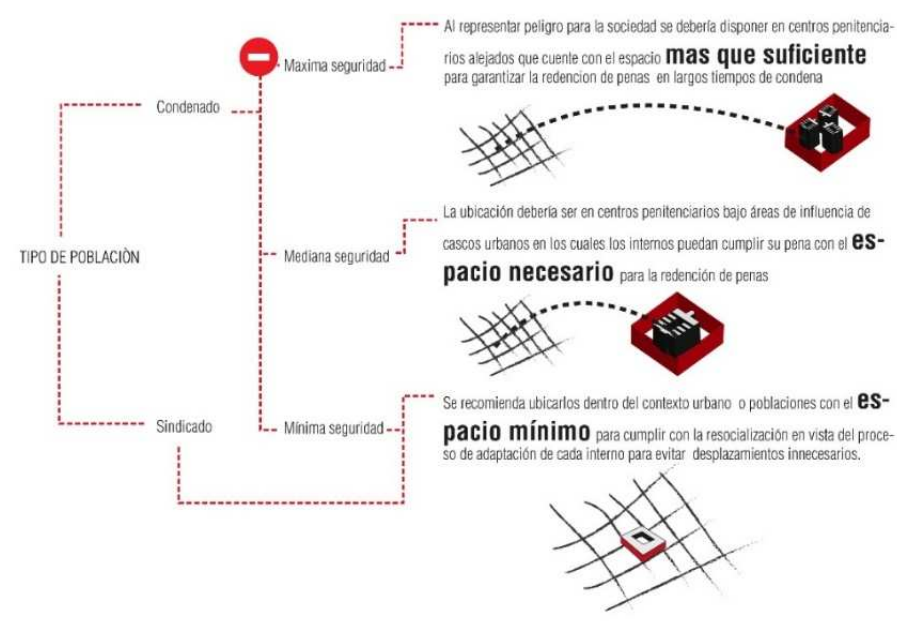

Figura 4.5: Pertinencia de las cárceles según su capacidad y usuario en contextos urbanos, elaboración propia.

La imagen 10 hace énfasis en que el tipo de población es importante y va directamente relacionado con el tamaño y la ubicación del establecimiento el cual debería ser proyectado dejando como conclusión preliminar que no todas las cárceles pueden ser iguales debido a sus requerimientos y caracterizaciones individuales.

\section{LA CÁRCEL Y LA AFECTACIÓN URBANA}

Teniendo definida la clasificación se construye una matriz que evalué impactos en sus contextos inmediatos, para evaluar el impacto de estas infraestructuras es necesario plantear criterios de evaluación, por lo cual se escoge a el autor Jan Bazant ${ }^{10}$ en sus criterios define metodologías de análisis para temáticas urbanas, se modifican algunos de los criterios postulados por el autor y se proponen otros consolidando los componentes de evaluación de la siguiente forma:

- Zonificación: determinar la vocación del sector, la compatibilidad de usos del suelo periférico y relaciones con el entorno de la cárcel.

- Perímetro: toda aquella afectación en la franja perimetral, como la percepción de seguridad y la contaminación.

- Accesibilidad: la ubicación y su facilidad de accesibilidad al equipamiento se evaluará desde el componente vial y sus distancias

- Demanda: las cárceles son edificios de un número considerable de usuarios, por esta razón es necesario evaluar el componente de fácil vinculación al transporte, como también la suficiencia de plazas de acceso y parqueaderos para la capacidad diseñada.

- Potencialidad: para crear identidad y pertenencia es necesario explorar sobre potencialidades que puedan ofrecer los establecimientos y sus contextos.

A continuación se presenta ejemplos impacto de las cárceles en su contexto:

\footnotetext{
${ }^{10}$ JAN BAZANT S, profesor desde 1976, investigador titular de la UAM, Arquitecto con maestría en estudios avanzados en diseño urbano del Massachusetts Institute o Technology (MIT) y Doctorado en Urbanismo de la Universidad Nacional Autónoma de México (UNAM)
} 


\subsection{Resumen Análisis por forma vertical}

Càrcel Baureau Chicago, Estados Unidos
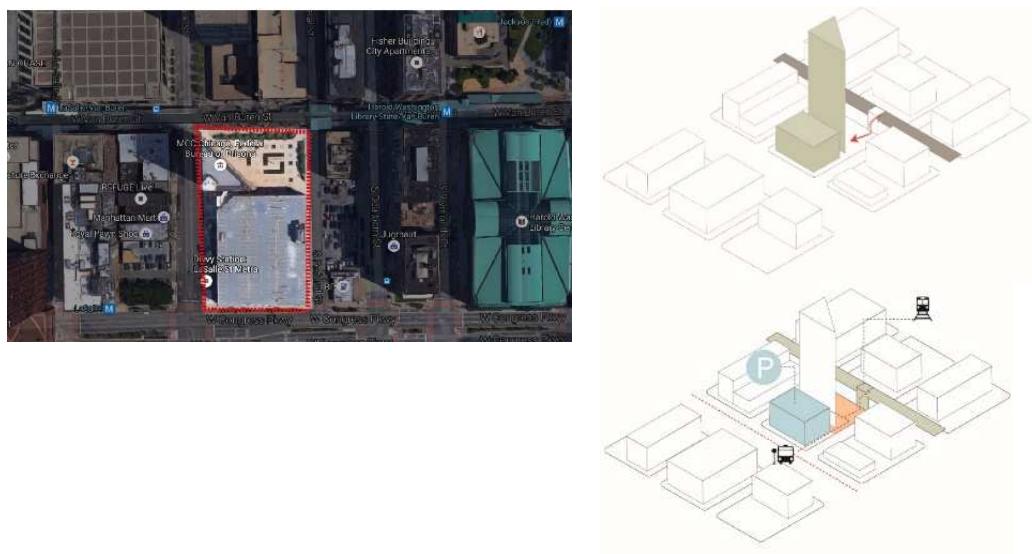

Figura 5.1: Cárcel Baureau Chicago. Fuente imagen google maps (izquierda)

Figura 5.1.1: Esquema de perímetro, elaborado por el autor (centro)

Figura 5.1.2: Esquema de demanda, elaborado por el autor (derecha)

Este proyecto cuenta con compatibilidad de usos de suelo en toda la zona, generando una relación vertical la cual es aprovechada por la simbiosis entre usos de juzgado y cárcel, dejando espacios necesarios para plaza de recibo en primera planta, la cual está integrada al sistema de transporte masivo metro.

\subsection{Resumen Análisis por forma horizontal}

Cárcel la Modelo- Bogotá, Colombia
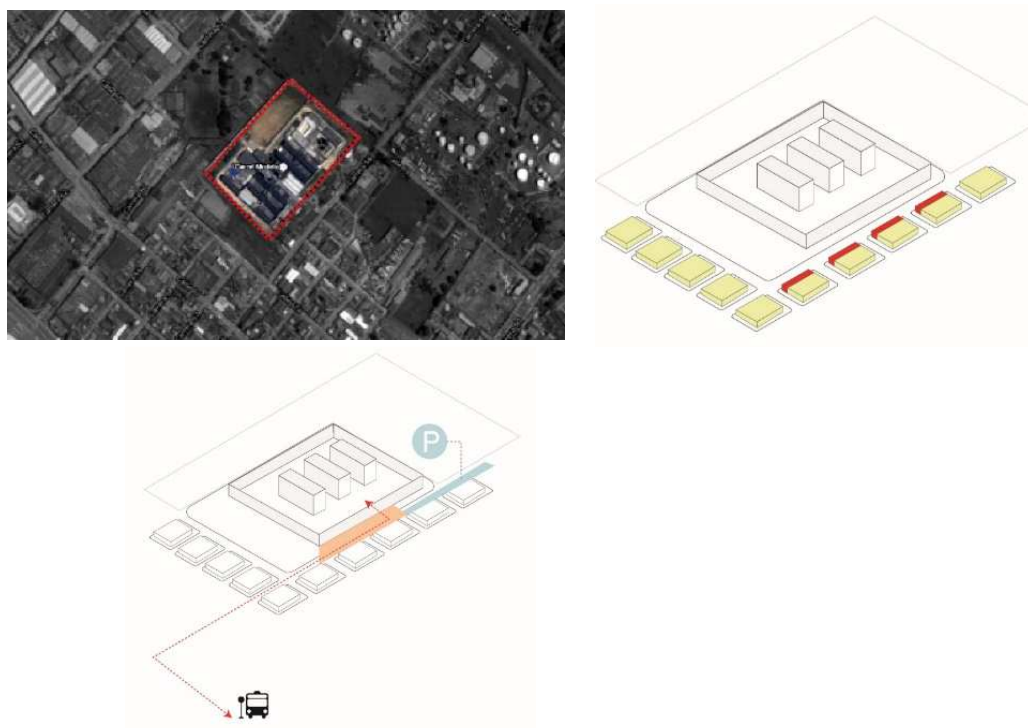

Figura 5.2: Cárcel la Modelo Bogotá. Fuente imagen google maps (izquierda)

Figura 5.2.1: Esquema de perímetro, elaborado por el autor (centro)

Figura 5.2.2: Esquema de demanda, elaborado por el autor (derecha) 
Este proyecto no tiene relación con el entorno, las largas distancias propician que se generen focos de desechos y que se consolide una percepción de inseguridad, la vía principal cumple las funciones de plaza improvisada restringiendo el uso público.

\subsection{Resumen Análisis por nivel de seguridad alto}

Cárcel de Combita- Boyacá, Colombia
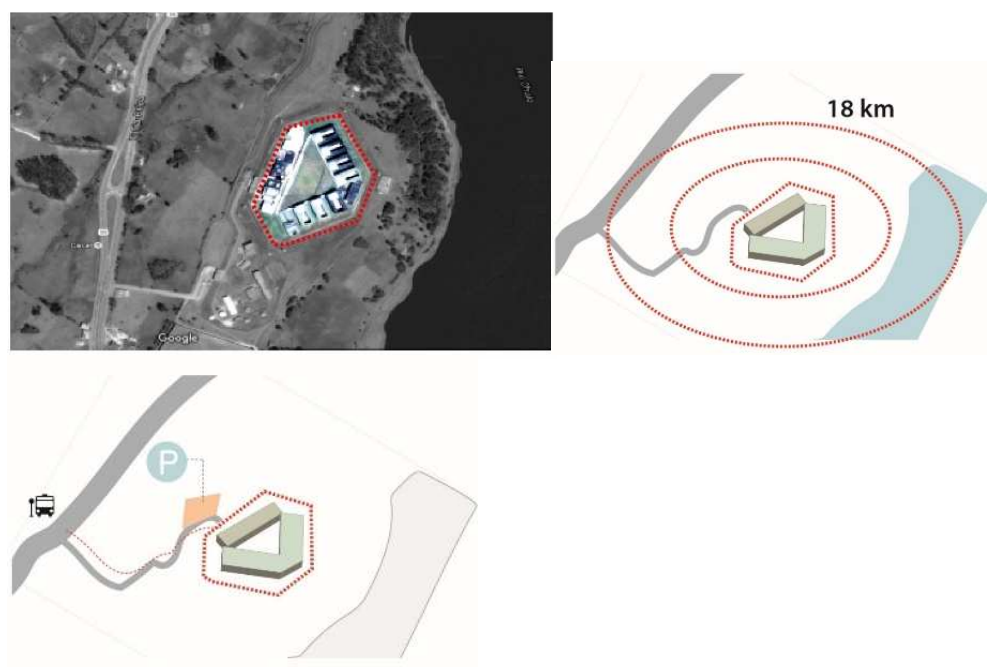

Figura 5.3: Cárcel de Combita, Boyacá. Fuente imagen google maps Figura 5.3.1: Esquema de perímetro, elaborado por el autor (centro) Figura 5.3.2: Esquema de demanda, elaborado por el autor (derecha)

El tamaño y la ubicación es un problema de planificación, El municipio más cercano se encuentra a $18 \mathrm{~km}$ del establecimiento, creando el desplazamiento de personal permanente en sus inmediaciones; la capacidad de población de la cárcel es mayor a la del municipio propiciando desarrollo informal en sus inmediaciones por la cantidad de usuarios.

\section{4 resumen Análisis por nivel de seguridad medio}

Cárcel de Bellavista- Cali, Colombia
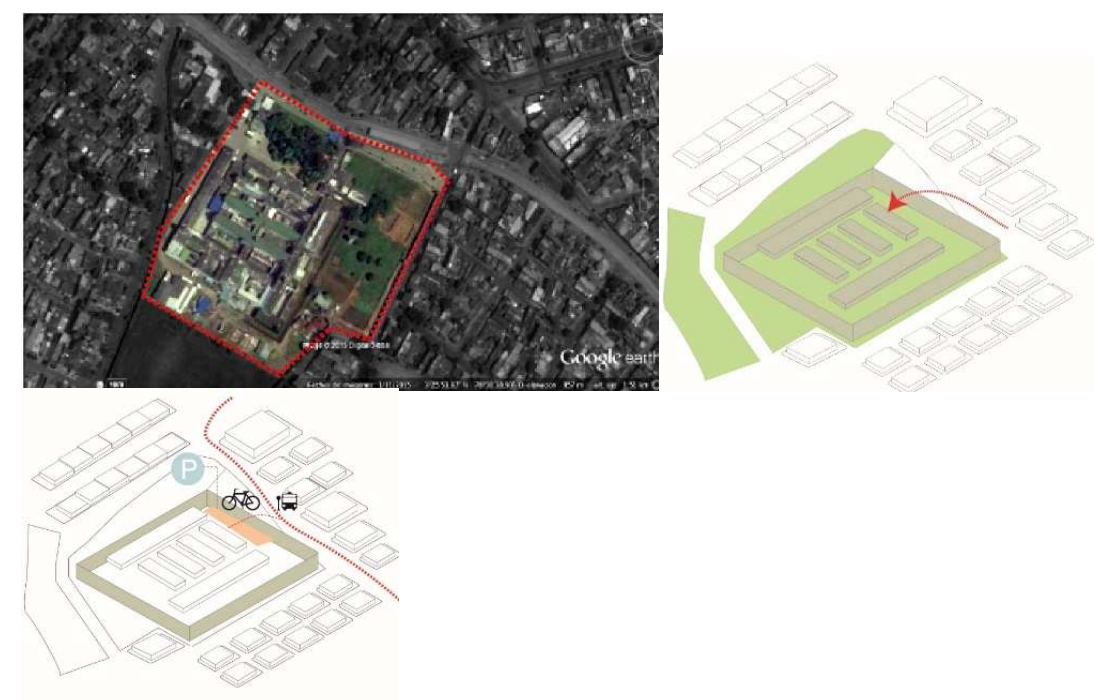

Figura 5.4: Cárcel de Bellavista, Cali. Fuente imagen: google maps Figura 5.4.1: Esquema de perímetro, elaborado por el autor (centro) Figura 5.4.2: Esquema de demanda, elaborado por el autor (derecha) 
Este proyecto tiene un problema de relaciones periféricas, al tener vivienda en sus inmediaciones propicia la posibilidad de un tráfico de elementos desde el exterior arrojados hacia el interior de los patios de la cárcel. Por otro lado La contaminación es alta debido a que algunos de los lotes periféricos son vacíos lo cual genera acumulación de escombros basuras y plagas.

\subsection{Resumen Análisis por nivel de seguridad mínima}

Bastoy prison, Noruega

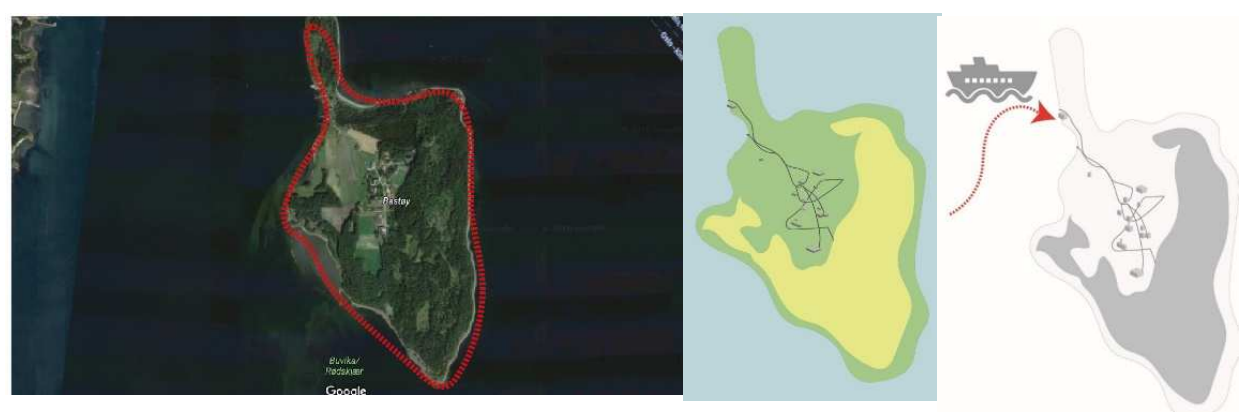

Figura 5.5: Cárcel de Bastoy, Noruega. Fuente imagen google maps Figura 5.5.1: Esquema de perímetro, elaborado por el autor (centro)

Figura 5.5.2: Esquema de demanda, elaborado por el autor (derecha)

El suelo de la isla es aprovechado eficientemente para la redención de penas de los internos y la generación de autosuficiencia del establecimiento. Una de las desventajas del total aislamiento en el que se encuentra la isla, lo cual genera desplazamiento de infraestructura y de

personal

continuo

hacia

la

isla.

\subsection{Resumen análisis por capacidad grande (más de 1500 internos)}

Cárcel la Picota. Bogotá, Colombia (4931 reclusos)
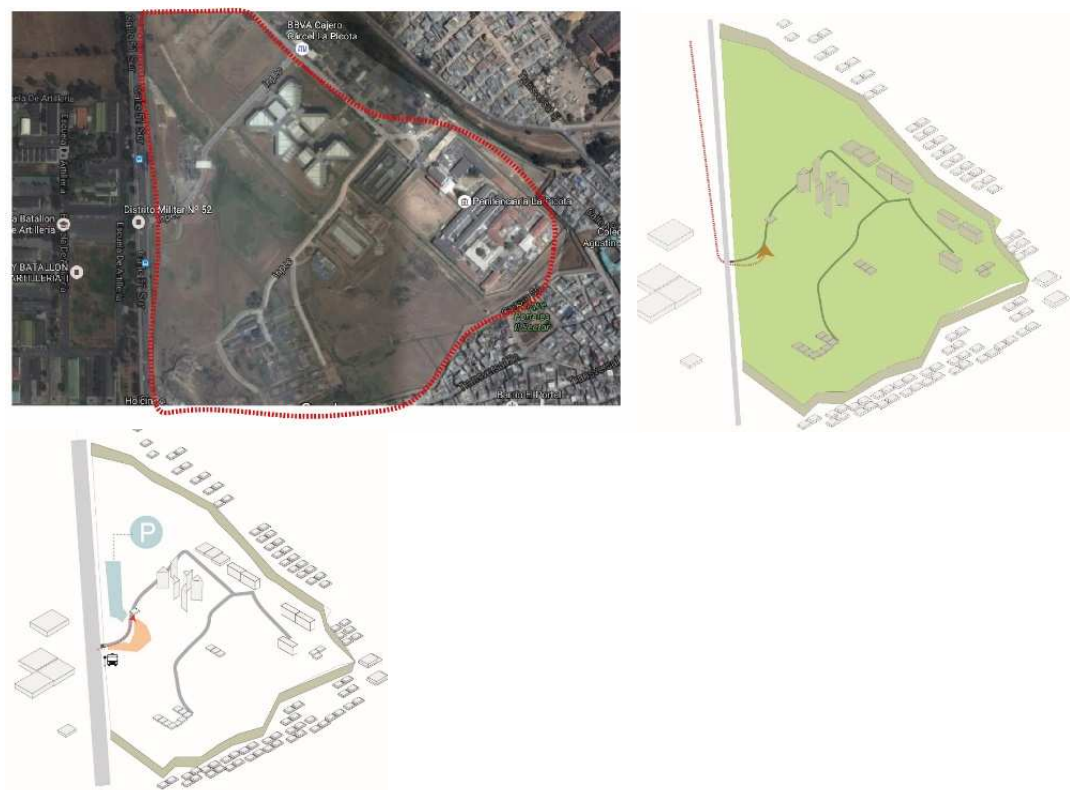

Figura 5.6: Cárcel la Picota, Bogotá. Fuente imagen google maps

Figura 5.6.1: Esquema de perímetro, elaborado por el autor (centro)

Figura 5.6.2: Esquema de demanda, elaborado por el autor (derecha) 
Las relaciones con el entorno son conflictivas, debido a que el cerramiento no permite la interacción entre equipamiento y la ciudad. Uno de los aportes de este proyecto es la plaza de recibo, debido a la dimensión y disposición de servicios básicos completamente organizados para los altos tráficos de personal de visita.

\subsection{Resumen análisis por capacidad mediana (entre 500 y 1500 internos)}

Cárcel el Buen Pastor. Bogotá, Colombia (1270 reclusos)
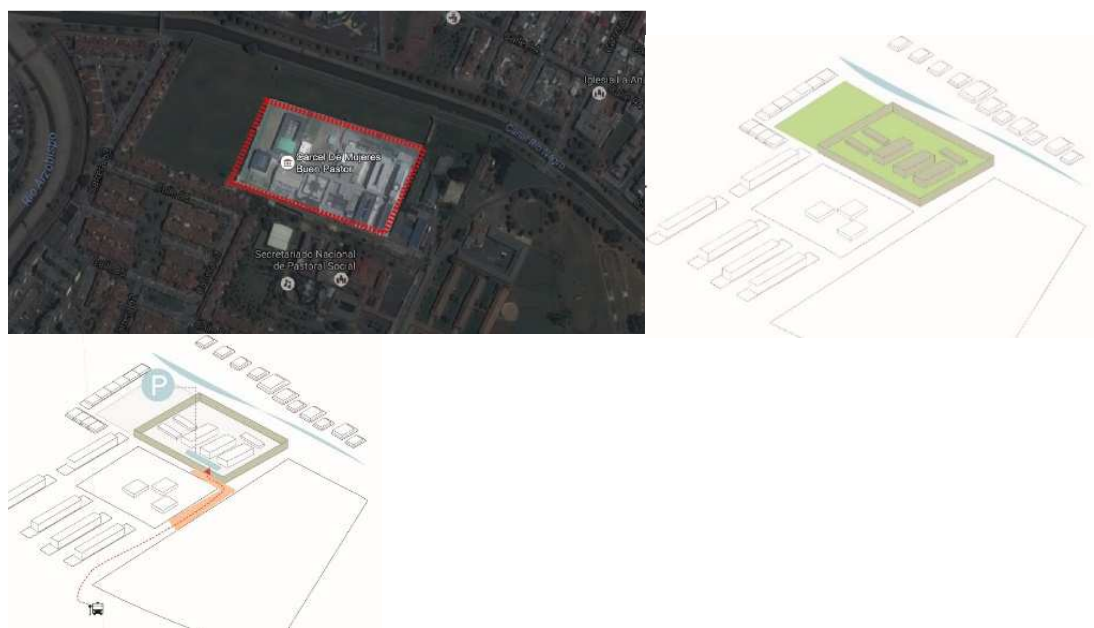

Figura 5.7: Cárcel Buen Pastor, Bogotá. Fuente imagen google maps Figura 5.7.1: Esquema de perímetro, elaborado por el autor (centro) Figura 5.7.2: Esquema de demanda, elaborado por el autor (derecha)

El acceso no es el adecuado para la cantidad de visitas. Además a esto la vía principal no tiene la sección necesaria para recibir y organizar el volumen de visitas del equipamiento generando relación de usos conflictiva en sus inmediaciones.

\subsection{Resumen nálisis por capacidad baja (menos de 500 internos)}

Cárcel el Bay View. New York, Estados Unidos (320 reclusos)
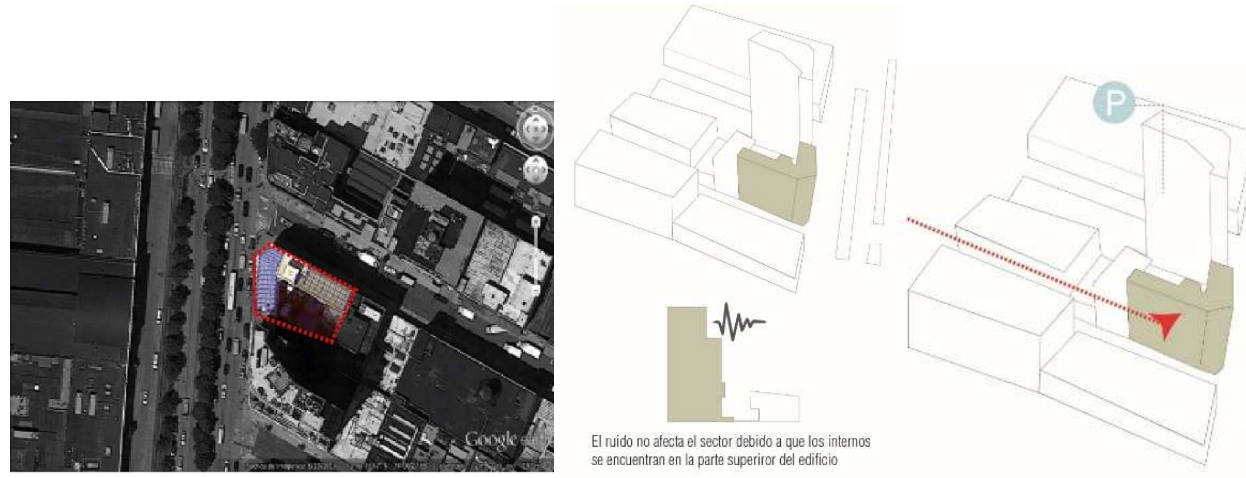

Figura 5.8: Cárcel Bay View. New York. Fuente imagen google maps Figura 5.8.1: Esquema de perímetro, elaborado por el autor (centro) Figura 5.8.2: Esquema de demanda, elaborado por el autor (derecha) 
La cárcel se encuentra en un sector comercial en el cual predominan los talleres de arte y tiendas de ropa, por estar en una zona temática es muy trascurrida. La calle toma vida con mobiliario urbano y vegetación en la cual las fachadas activas generan la circulación permanente de peatones generando que el apropiamiento del sector.

\subsection{Resultados}

Teniendo estos criterios se evaluaran los componentes de clasificación mencionados en el capítulo 4, los cuales son cárceles por forma, capacidad y por nivel de seguridad, mediante evaluación de situación ${ }^{11}$ por medio de calificación numérica entre 1 y 3 en la cual las clasificaciones serán:

- el numero 1 situación conflictiva

- el numero 2 situación neutra

- el numero 3 situación de aporte

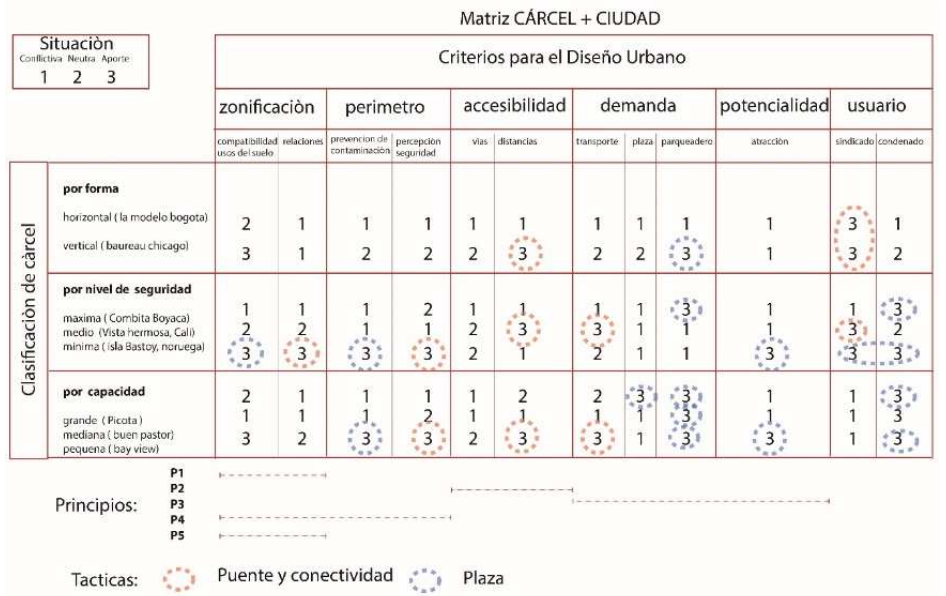

Figura 5.9: resultado de la matriz, elaboración propia.

\section{PRINCIPIOS}

A continuación se presentan los principios para las problemáticas encontradas:

\subsection{Principio 1, Proporción del equipamiento con el contexto}

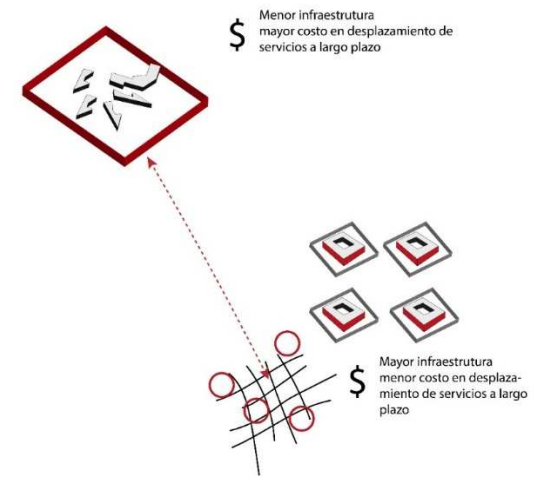

Figura 6.1: proporción sobre y ubicación y tamaño de cárceles, elaboración propia.

\footnotetext{
${ }^{11}$ se aclara que no se incluye la clasificación por tipo de población debido a que esta clasificación no genera requerimientos físicos diferentes a las clasificaciones anteriormente mencionadas.
} 
La proporción del establecimiento con su contexto es importante debido a que de allí parte la inversión de intervención, los terrenos alejados generan conflictos de desplazamiento de infraestructura y personal requerido.

\subsection{Principio 2, Compensación de distancias}

La compensación de distancias permite aislar la contaminación auditiva y visual como también le aporta a la planeación del espacio urbano mediante la amortiguación de áreas las cuales se pueden adaptar para el uso común.
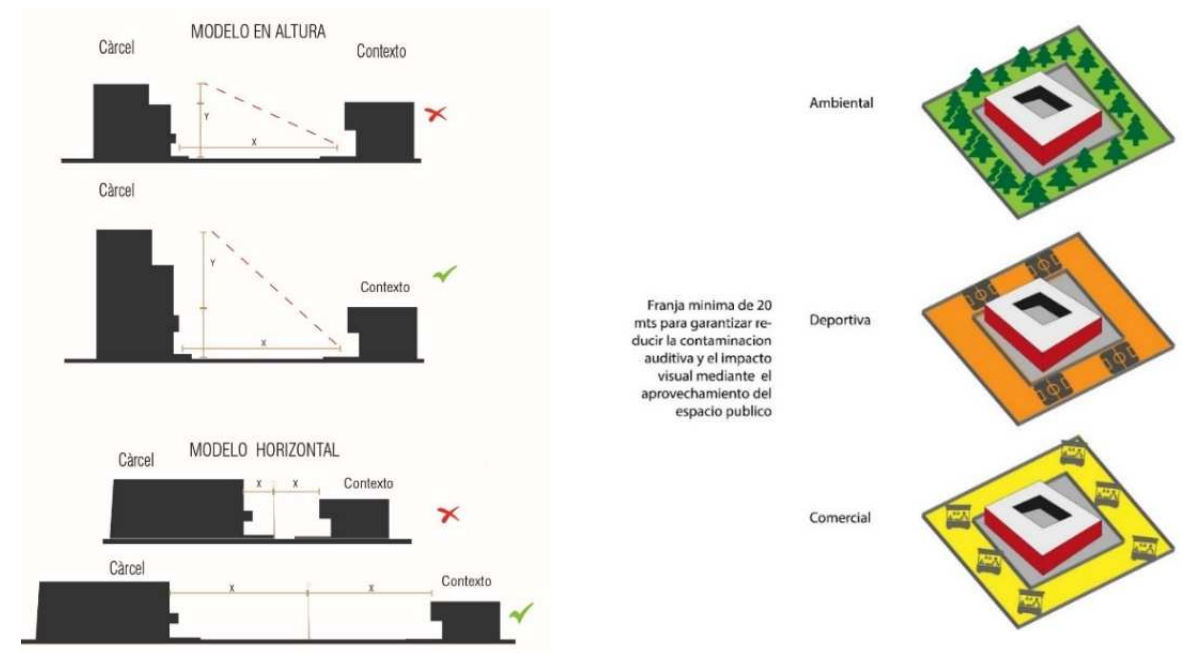

Figura 6.2: compensación de distancia en modelo vertical y horizontal con usos, elaboración propia (izquierda)

Figura 6.2.1: implementación nuevos usos periféricos, elaboración propia (izquierda)

El tratamiento de los bordes de las cárceles se puede asimilar como el de los parques, en principio rodear estos espacios con múltiples actividades a distintas horas con la característica de generar una seguridad visual.

\subsection{Principio 3. Amortiguamiento funcional}

La cárcel y su funcionamiento con el tiempo va generando nuevos usos perimetrales, Este principio lo que busca es la contemplación inicial de actividades previstas modificando el uso inmediato de los predios colindantes a la cárcel como planeación inicial debido a que la cárcel necesita funciones inmediatas a su carácter, dentro de estas demandas de comercio entre los cuales están zonas de parqueo de personal del establecimiento y de los usuarios de visita, papelerías, comunicaciones, cafeterías, alimentación y la demanda hotelera que surge alrededor de los días de visita. 
dentro del contexto urbano,

la franja de impacto de la

cárcel plantea la modificacion de usos emegertes o no previstos debido a la deman-

da especifica del estableci-

miento.

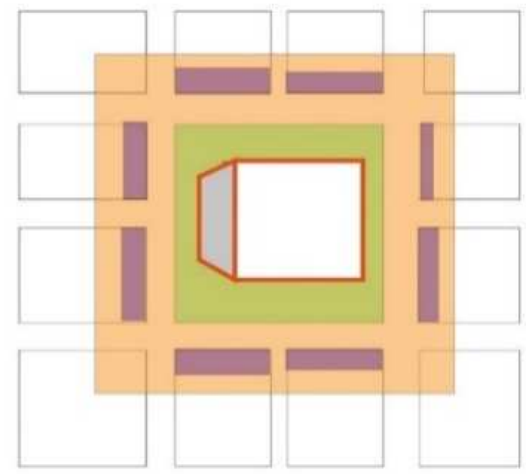

Figura 6.3: la cárcel y su área de influencia inmediata, elaboración propia.

\subsection{Principio 4, aprovechamiento vertical.}

Este principio solo es aplicable en el modelo de cárceles en altura; considerando el alto costo de los predios se recomienda explotar la propiedad vertical, la zonificación vertical soluciona las problemáticas de servidumbre que genera el establecimiento como también de esta forma se puede mitigar la contaminación auditiva disponiendo a los internos en los últimos niveles.

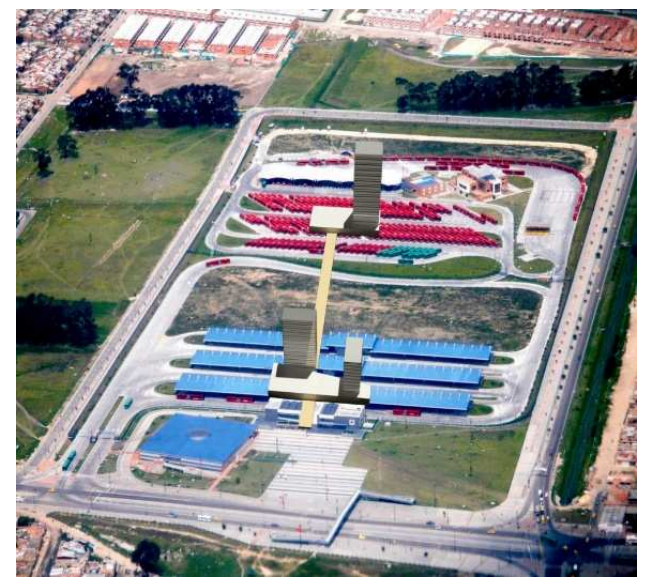

Figura 6.4: esquema de aprovechamiento en altura de los patios de Transmilenio transporte masivo Bogotá para cárceles en altura. Elaboración propia.

\subsection{Principio 5, zonificación vertical.}

La zonificación por niveles significa considerar compatibilidad de funciones por niveles, junto con posible unión entre edificios para garantizar la multiplicidad de funciones con aprovechamiento en altura. Considerando la aplicación de este principio se descongestionaría el espacio en primera planta.

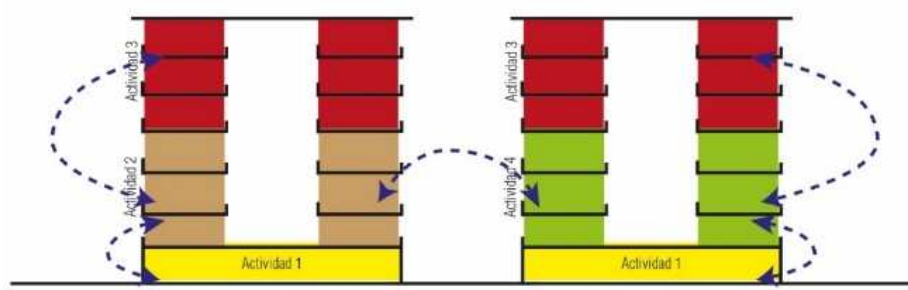

Figura 6.5: esquema de zonificación vertical, elaboración propia. 
En este ejemplo de cárcel el color amarillo representa todos los usos públicos como oficinas y módulos administrativos, el color verde y naranja representa usos básicos como talleres, cocinas entre otros y el color tojo representa el lugar de reclusión generando jerarquías de funciones y de niveles de seguridad verticalmente

\section{PROPUESTAS PARA INTERVENCION PARA ESTABLECIMIENTOS CARCELARIOS}

A continuación se presentan soluciones sobre conflictos generalizados en los establecimientos carcelarios:

\subsection{Integración de los equipamientos:}

La cárcel es en sí misma un micro ciudad, con edificios internos que satisfacen todas las necesidades diarias de los internos, dentro la cual se compone de infraestructura de salud, educativa, talleres y cocinas principalmente. El cerramiento genera que se cierre el equipamiento hacia el interior por modelos de seguridad generando que se pierda la conexión con la ciudad, La integración de estos equipamientos se puede dar con ciertas características. El siguiente planteamiento es una cárcel de mínima seguridad con población a punto de cumplir su condena. en la cual se ubican los componentes en sus esquinas para que se puedan generar relaciones funcionales entre módulos buscando multifuncionalidad de usuario, menor inversión y aprovechamiento de infraestructura un ejemplo seria el edificio que se crea para cocina de la cárcel convertirlo en un equipamiento comunitario para la comunidad desde las dimensiones urbanística, paisajística, arquitectónica, espacial y social.
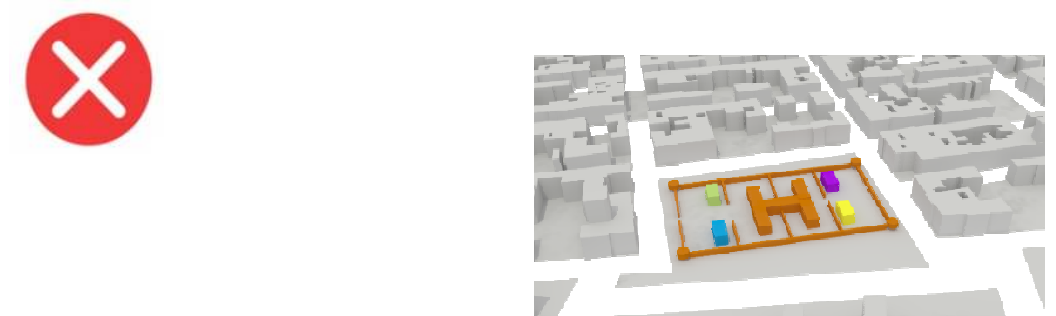

Figura 7.1: esquema cárcel con componentes hacia el interior, esquema de elaboración propia
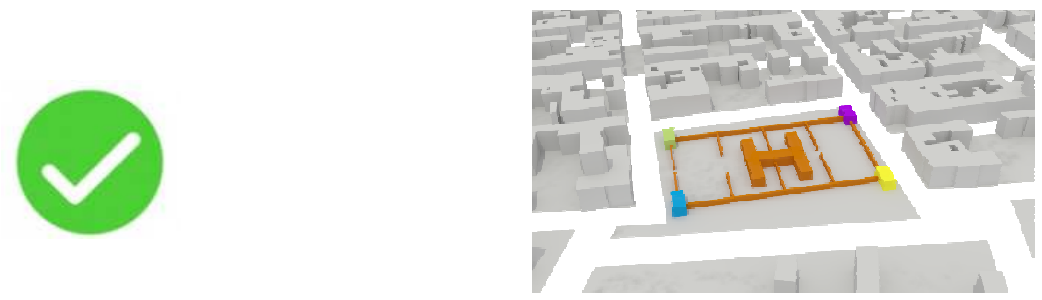

Figura 7.1.1: esquema cárcel con componentes hacia el exterior, esquema de elaboración propia 


\subsection{Las plazas de recibo de los establecimientos carcelarios:}

Las visitas generan conflictos de contaminación por encontrarse a la intemperie y genera acumulación de personas sobre la vía pública, La falta de mobiliario espacio público y parqueaderos afecta la organización. Por otro lado el comercio inmediato genera actividad en el sector aportando con el principio de seguridad visual.

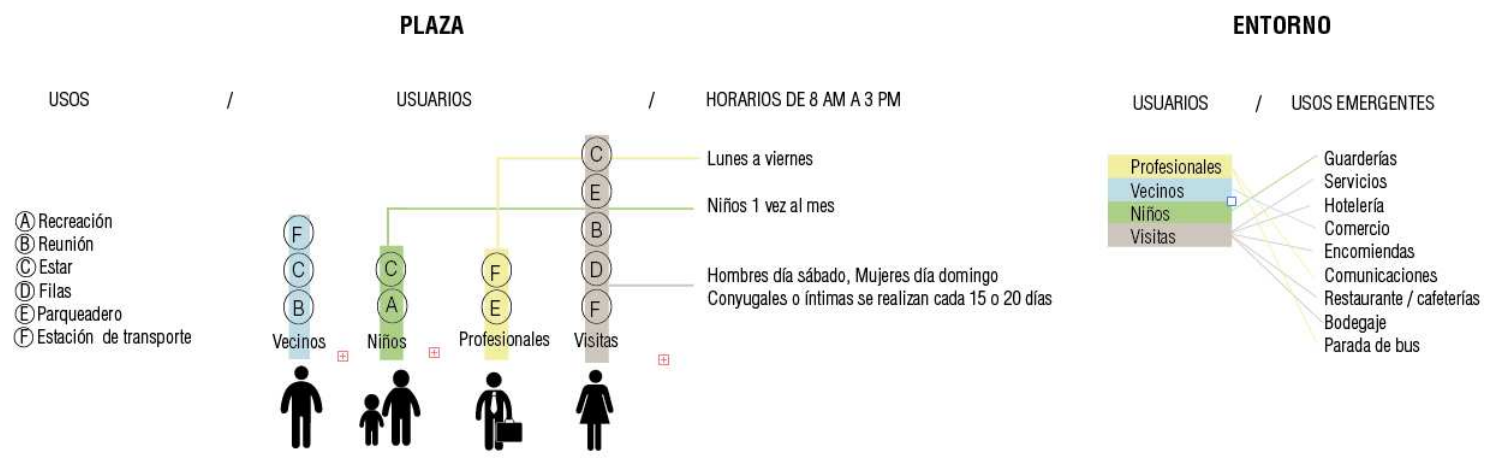

Figura 7.2: Consideraciones al diseñar una plaza de acceso a una cárcel, elaboración propia.

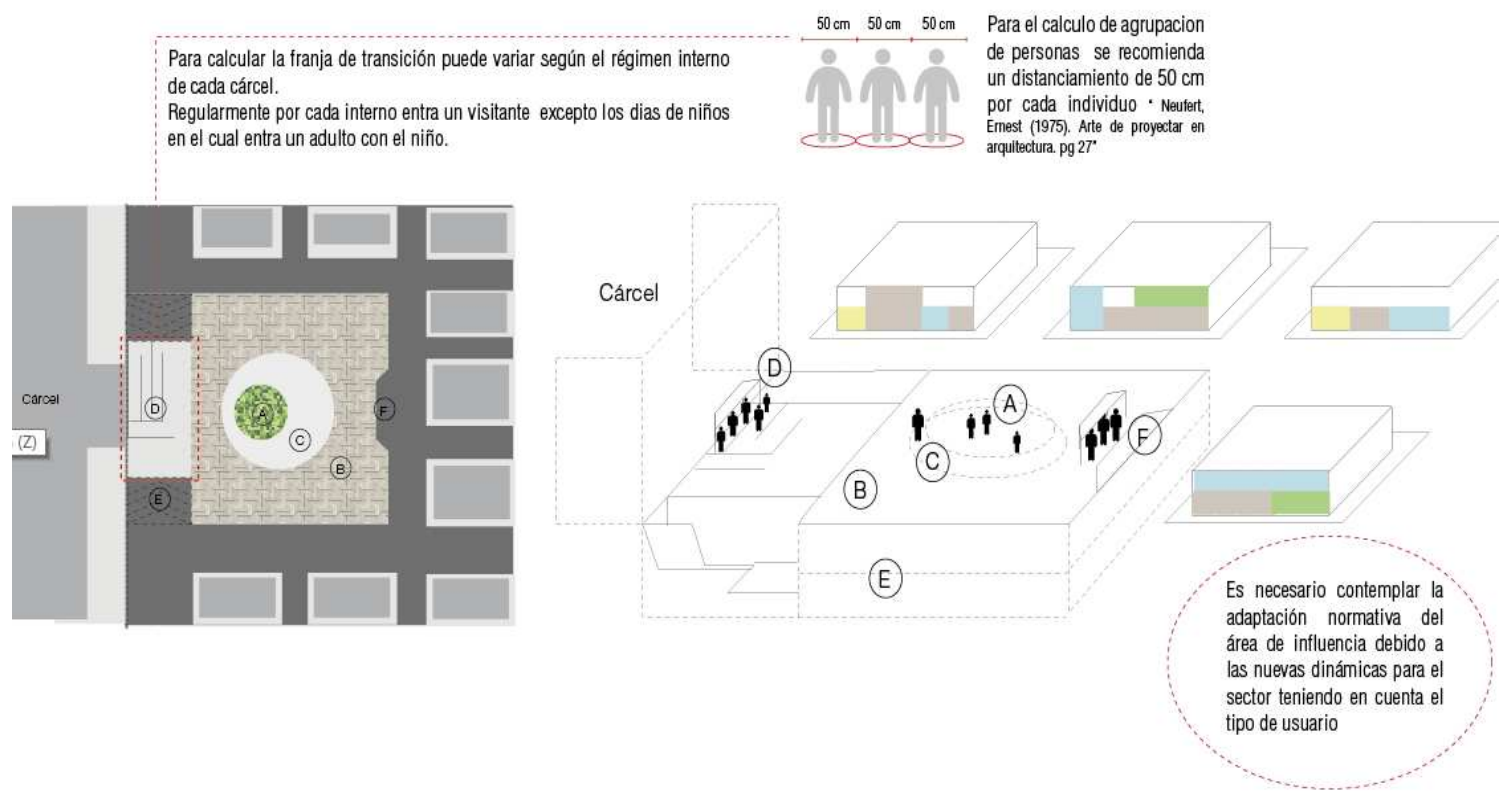

Figura 7.2.1: Consideraciones al diseñar una plaza de acceso a una cárcel, elaboración propia.

\subsection{Demanda de servicios:}

El entorno inmediato de las cárceles entra en conflicto cuando no se consideran elementos de demanda de servicios, en este caso se genera en vez de un edifico de garita un espacio mixto para guardería de los niños en días de visitas. Todas estas demandas que no se contemplan desde la planeación deben ser atendidas para que el impacto sea mínimo. Dentro de estos componentes a solucionar tenemos la insuficiencia de espacios de plaza de acceso a estos centros penitenciarios, la carencia de espacios para parqueo, espacios complementarios entorno a las visitas como cafeterías, comercio formal e informal entre otros componentes los cuales con su ausencia generan que se haga latente la afectación de las cárceles en sus contextos. 


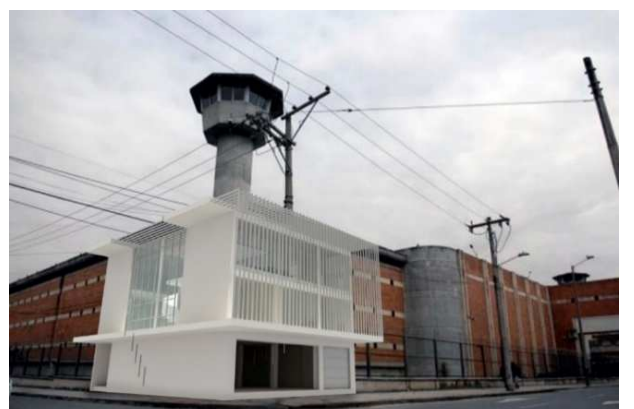

Figura 7.3: solucionando demandas de servicio, cárcel distrital de Bogotá, montaje elaboración propia.

\subsection{Intercambio como regulación de la sociedad:}

Gran parte de la cárcel la conforma su cerramiento, espacio longitudinal que se deteriora por la falta de uso, en este caso se plantea generar una plataforma comercia para comercializar los productos locales y los que producen los talleres de la cárcel, es posible generar alternativas que aporte a reducir la agresividad de las cárceles y se de una relación permanente con las comunidades a las cuales pertenecen.

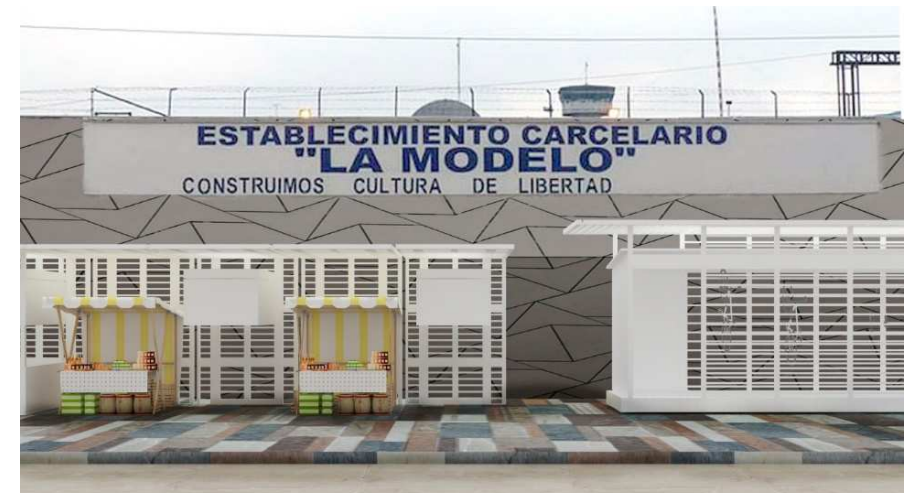

Figura 7.4: posible solución al cerramiento agresivo, cárcel la modelo Bogotá, montaje elaboración propia.

\subsection{Tratamiento del paisaje y aprovechamiento del espacio:}

Las grandes áreas de amortiguamiento funcionales de las cárceles generan que se vuelvan áreas inertes, en este caso se plantea aprovechamiento con floricultivos para dar un tratamiento al cerramiento agresivo mediante el paisajismo. De esta forma el suelo no dejaría de ser productivo y se podría dar integración del equipamiento con su contexto.

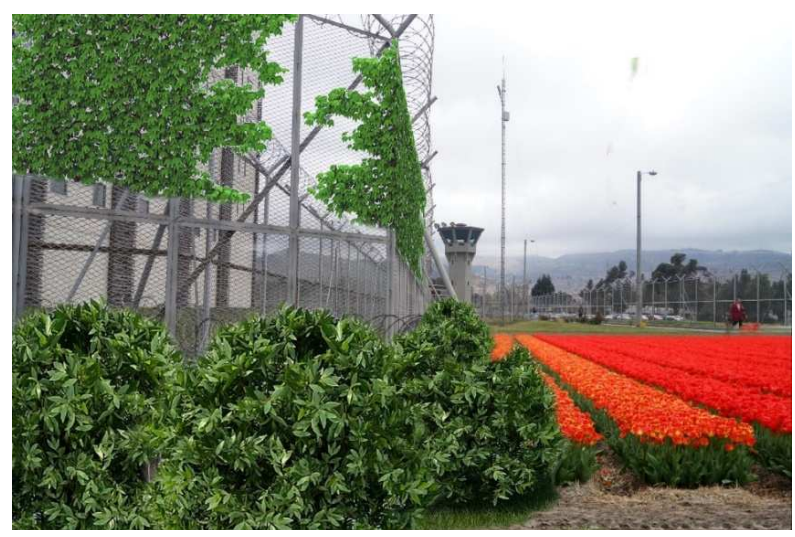

Figura 7.5: cerramiento cárcel la picota productiva, reduciendo la agresividad. Montaje elaboración propia. 


\subsection{Accediendo y conectando, reutilizando cárcel}

Para los predios disponibles o cárceles existentes, se propone implantar nuevos modelos de cárcel definidos, las cuales tengan en cuenta características básicas de accesibilidad y que puedan ofrecer espacios a la demanda inmediata y a la comunidad como nueva generación de infraestructura carcelaria.
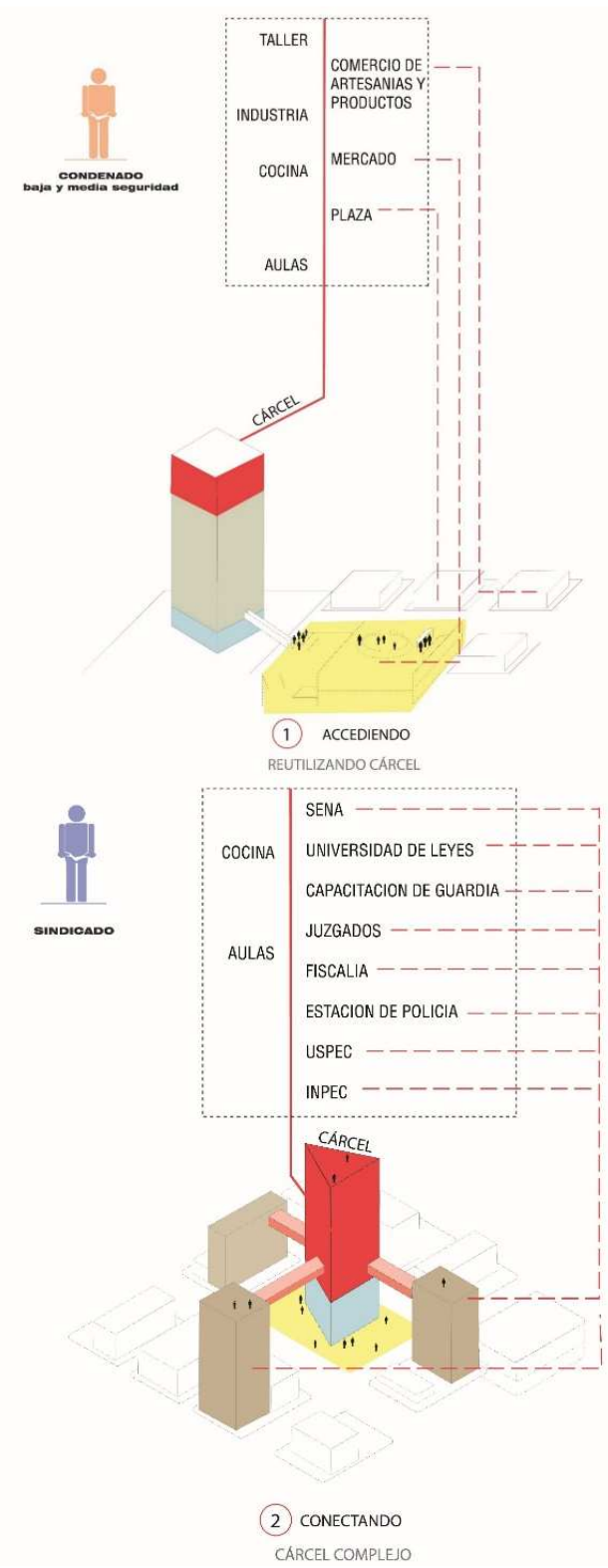

Figura 7.6: cárcel para población condenada, elaboración propia (izquierda)

Figura 7.6.1: cárcel para población sindicada, elaboración propia. (Derecha)

La interacción directa entre edificios permite reducir interrupción de procesos los cuales desgastan el sistema carcelario. Unir edificios mediante elementos como puentes los cuales conecten nuevas posibilidades de usos, da nuevas dinámicas de organización de ciudad en la cual la cárcel ofrece servicios y la sociedad recibe beneficio de esta inversión reciproca en infraestructura. 


\subsection{Usando e integrando, cárcel equipamiento}
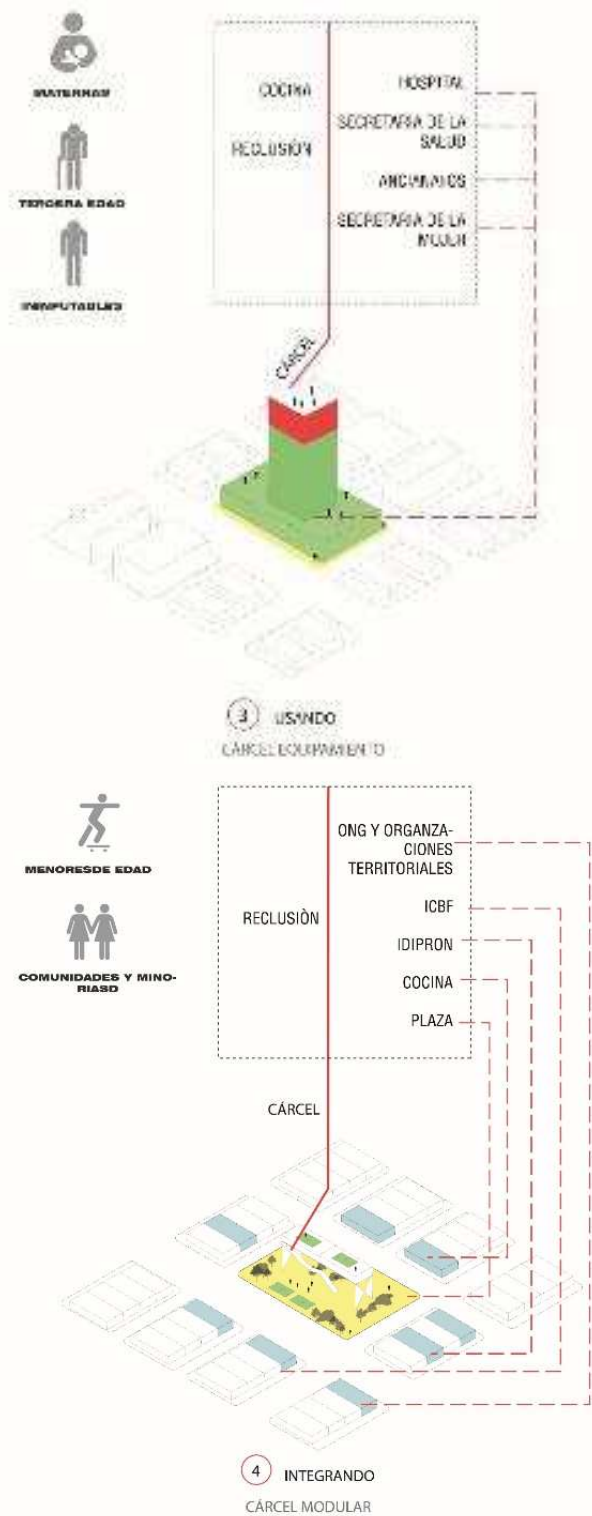

Figura 7.7: modelo cárcel equipamiento comunitario, elaboración propia (izquierda)

Figura 7.7.1 cárcel modular, elaboración propia (derecha)

\section{CONCLUSIONES PRELIMINARES}

Las cárceles suelen ser grandes paquetes urbanos, de largos perímetros, que dificultan la permeabilidad en planta baja dentro de la trama urbana. Es necesario abordar alternativas a estos equipamientos como edificios en altura, modulares o de bajo impacto.

La prisión es un tema amplio e interdisciplinario, tanto como para la administración del mismo y para la planificación del proyecto urbano, se tiene que considerar la participación de arquitectos, diseñadores urbanos, urbanistas como también educadores, politólogos, filósofos, sociólogos y psicólogos junto con el poder político. Por esta razón se considera complejo y un 
reto muy importante poder lograr consolidar zonas de actuación especial con el motivo de construir armonía social.

La infraestructura carcelaria demanda gran infraestructura de servicios públicos por esta razón algunas necesitan estar inmersas dentro de contextos urbanos, las únicas cárceles que si se deben contemplar fuera de las áreas urbanas son las de alta seguridad, las cárceles de gran tamaño, cárceles para población indígenas relacionados con programas de producción del suelo o cualquier población de régimen especial que demande espacio para cumplir sus funciones.

Determinar actores y demandas de las cárceles junto con sus relaciones funcionales, ayuda al crecimiento planificado de la ciudad.

\section{BIBLIOGRAFÍA}

FOUCAULT, MICHAEL. (1975) Vigilar y castigar: nacimiento de la prisión.- 1a, ed.-Buenos Aires: Siglo XXI Editores Argentina

CLAVAL, PAUL (1982) Espacio y poder-1ae ed. - ed.- fondo de cultura económica México, D.F

JAN BAZANT S, Jan. (2006) Manual de Diseño Urbano. Editorial trillas. Sexta edición. Reimpresión. 2006. México.

JANE JACOBS (1967) Muerte y Vida de las grandes ciudades- publicado por Capitán Swing Libros S.I, 2011

PLAZA DELGADO, OSCAR (2012). La necesidad de creación de una cárcel sustentable para la verdadera reinserción (tesis de pregrado licenciatura en derecho). Universidad nacional autónoma de México.

BALDACCI, ANDREA (2014). La cárcel. Un nuovo carcere per Bogotá (tesis de posgrado corso di laurea specialist/magistrale a ciclo único in architettura- universita'di Bologna

LÓPEZ MEJÍA, JAIME (2013). La arquitectura como recurso para la resocialización en las cárceles colombianas. (Tesis de grado de arquitectura) pontificia universidad javeriana facultad de arquitectura y diseño

MANUAL PAUTAS MÍNIMAS DE DISEÑO (2014) USPEC- unidad de servicios penitenciarios y carcelarios,

DOCUMENTO INPEC - pautas carcelarias 2012

COLOMBIA LEY 1709 DE 2014, Por medio de la cual se reforman algunos artículos de la ley 65 de 1993, DE la ley 599 de 2000, de la ley 55 DE 1985 y se dictan otras disposiciones, presidencia de la república. 